\title{
Poxvirus-based active immunotherapy synergizes with immune checkpoint inhibitors to cause tumor regression and extend survival in preclinical models of cancer
}

\author{
Susan P Foy, Ryan B Rountree*, Joseph Cote, Tracy dela Cruz, Evan Gordon, Erica Trent, Alex Franzusoff, \\ James B Breitmeyer, Stefanie J Mandl
}

From Society for Immunotherapy of Cancer 29th Annual Meeting

National Harbor, MD, USA. 6-9 November 2014

Combining poxvirus-based immunotherapies which "step on the gas" to activate tumor antigen-specific $\mathrm{T}$ cell immune responses with immune checkpoint inhibitors (ICIs) which "release the brakes" on the immune system is a promising direction for enhancing cancer immunotherapy. Evidence for the potential clinical benefit from combination immunotherapy was obtained in a Phase I dose escalation trial. Cohorts of prostate cancer (mCRPC) patients were treated with a fixed dose of PROSTVAC, a poxvirus-based active immunotherapy, plus escalating doses of Ipilimumab, an anti-CTLA-4 ICI. The median overall survival (mOS) of 31.6 months [1,] from the combined cohorts was notably longer than the mOS of mCRPC patients from an independent randomized Phase II study (PROSTVAC alone 25.1 months versus placebo 16.6 months; the most pronounced survival benefit (8.5 months) in mCRPC to date) [2]. This potentially synergistic combination of PROSTVAC and Ipilimumab warrants further exploration.

We modeled the benefit of combining poxvirus-based immunotherapy with CTLA-4 blockade using MVA-BNHER2, which is being developed for breast cancer. In preclinical studies a dramatic increase in mOS was observed in a therapeutic CT26-HER2 lung metastasis model when mice were treated with MVA-BN-HER2 plus CTLA-4 blockade compared to either treatment alone. The improved survival with the combination therapy was accompanied by a striking increase in the magnitude and functional quality of tumor infiltrating HER-2 specific CD8 T cells [3].

Bavarian Nordic, Inc., USA
Additional ICIs are identified in our preclinical studies as promising candidates for combining with poxvirusbased immunotherapies. Immune checkpoint protein expression is normally induced on activated $\mathrm{T}$ cells to regulate activity, and we found that MVA-BN-HER2 treatment resulted in activated CD8 $\mathrm{T}$ cells and elevated expression of PD-1, TIM-3, or ICOS. However, immune checkpoint proteins are chronically elevated on exhausted $\mathrm{T}$ cells in an immunosuppressive tumor microenvironment. In untreated tumor-bearing mice, a potentially exhausted $\mathrm{T}$ cell phenotype was found on CD4 and CD8 $\mathrm{T}$ cells characterized by increased expression or coexpression of PD-1, TIM-3, and LAG-3. We compared treatment of MVA-BN-HER2 alone or in combination with ICI antibodies against these immune checkpoint molecules in solid or metastatic CT26-HER2 tumor models. Improved survival was observed with several different combinations, and synergistic efficacy was indicated using the Chou-Talalay method [4]. These studies provide data and rationale for combining poxvirus-based immunotherapies with a variety of ICIs in the clinic.

\section{Published: 6 November 2014}

References

Madan RA, et al: I pilimumab and a poxviral vaccine targeting prostatephase 1 dose-escalation trial. Lancet Oncol 2012, 13(5):501-508.

Kantoff PW, et al: Overall Survival Analysis of a Phase II Randomized Controlled Trial of a Poxviral-Based PSA-Targeted Immunotherapy in 28(7):1099-1105

Foy SP, et al: Submitted, and ASCO Annual Meeting 2014, Abstract 3013. 
4. Chou T-C: Combined Treatment of Pancreatic Cancer with Mithramycin A and Tolfenamic Acid Promotes Sp1 Degradation and Synergistic Antitumor Activity. Cancer Res 2010, 71(7):2793.

doi:10.1186/2051-1426-2-S3-P124

Cite this article as: Foy et al:. Poxvirus-based active immunotherapy synergizes with immune checkpoint inhibitors to cause tumor regression and extend survival in preclinical models of cancer. Journal for ImmunoTherapy of Cancer 2014 2(Suppl 3):P124.

Submit your next manuscript to BioMed Central and take full advantage of:

- Convenient online submission

- Thorough peer review

- No space constraints or color figure charges

- Immediate publication on acceptance

- Inclusion in PubMed, CAS, Scopus and Google Scholar

- Research which is freely available for redistribution

Submit your manuscript at www.biomedcentral.com/submit
C Biomed Central 